\title{
Effect of grazing by limpets on mid-shore species assemblages in northern Spain
}

\author{
J. Arrontes ${ }^{1, *}$, F. Arenas ${ }^{2}$, C. Fernández ${ }^{1}$, J. M. Rico ${ }^{1}$, J. Oliveros ${ }^{1}$, B. Martínez ${ }^{3}$, \\ R. M. Viejo ${ }^{3}$, D. Alvarez ${ }^{1}$ \\ ${ }^{1}$ Departamento de Biología de Organismos y Sistemas, Universidad de Oviedo, 33071 Oviedo, Spain \\ ${ }^{2}$ Marine Biological Association of the United Kingdom, Prospect Place, Plymouth PL1 2PB, UK \\ ${ }^{3}$ Área de Biodiversidad y Conservación, Escuela Superior de Ciencias Experimentales y Tecnología, \\ Universidad Rey Juan Carlos, 28933 Móstoles, Madrid, Spain
}

\begin{abstract}
Limpets were excluded from barnacle-dominated areas in 2 semi-exposed localities on the shore of northern Spain. We tested the hypotheses that a macroalgal canopy would develop and barnacle cover would decrease in exclusion quadrats. Spatial replication considered localities and sites within localities, while temporal replication considered 2 seasons of removal and 2 start dates within each locality and season. The experimental methods included exclusion quadrats (using fences), procedural controls (half fences) and untouched controls. Results supported both hypotheses. Limpet removal caused exclusion quadrats to change over time more than controls. An algal canopy dominated by Fucus vesiculosus developed and more barnacles were lost in exclusion quadrats than in controls. In addition, more trochids (largely Gibbula spp.) and whelks (Thais lapillus) were found in exclusion quadrats. Site effects were significant for virtually all variables analysed but no effect of locality, season or date was found. An indirect effect mediated by the development of an algal canopy appeared to be responsible for the loss of barnacles in exclusion quadrats. This indirect effect might have been reinforced by an additional indirect effect of algae mediated by increased densities of whelks under the algal canopy. Altogether, our results agree with those in semi-exposed shores in other parts of the world but not with results obtained in the west coast of Sweden, which has contrasting environmental conditions and a different dominant grazer species.
\end{abstract}

KEY WORDS: Grazing · Community structure · Indirect effects · Patella spp. · Fucus spp. - Spain

Resale or republication not permitted without written consent of the publisher

\section{INTRODUCTION}

It is well documented that the composition and dynamics of species assemblages in mid- and high tidal levels in rocky shores are strongly influenced by the activity of grazers (Hawkins \& Hartnoll 1983). The most evident effect of grazing at the high shore is the removal of macroscopic algal species leaving the primary substratum occupied by sessile animals; however, the assessment of the effect of grazers is far from being that simple. Even if we are limited to the direct removal of algae, there is an interaction between grazing and the effect of physical factors (Underwood 1980). The final effect depends on the mode of feeding of the grazers, the relative magnitudes of the feeding rate and the growth rate of the algae (Underwood \& Jernakoff 1981). At lower tidal levels or in areas with increased shading or wetness conditions, the relative importance of grazing as a structuring force may decrease as the growth rates of algae increase. Seasonal and spatial variation in the intensity of recruitment is an additional source of variability of the outcome of the interaction. In experimental shore ecology, there is ample evidence that timing of manipulations can significantly influence the rate of recovery and the species sequence. Examples abound and cover a great variety of habitats such as limpet dominated areas (Hawkins 1981), subtidal kelp forests (Kennelly 1987, 
Dayton et al. 1992), assemblages of geniculate coralline algae (Benedetti-Cecchi \& Cinelli 1994) or fucoid dominated beds (Kim \& DeWreede 1996). The effect of grazers is not, however, limited to the removal of algae and very often grazers can affect other animal species through competitive interactions (Underwood 1978, Dethier \& Duggins 1984). In this case, care must be taken when generalising because the intensity of competition may vary spatially and temporally in response to the densities and identities of competitors and availability of food (Underwood 1984). Grazers may also affect the rate of succession (e.g. Farrel 1991) or cause different assemblages to develop (e.g. Anderson \& Underwood 1997).

Apart from direct effects, indirect effects of grazers are common and have been profusely described in shore environments (e.g. Menge 1995). These indirect effects can usually be grouped into several types, one of which is habitat facilitation: the activity of one species promoting habitat transformation, which makes it suitable for colonisation by other species. In some cases, there is a dual effect of the key grazer on a third species, a direct deleterious effect through exploitative or interference competition and an indirect positive effect mediated by habitat facilitation (Menge 1995).

The structuring processes may vary between distant areas and, in fact, some studies report an important variability among different geographic zones even when they have equivalent species composition (Dethier \& Duggins 1988, Boaventura et al. 2002). Obviously, broad-scale comparisons of the effect of grazers are unavoidable in seeking generality of structuring forces in shore communities. However, making generalisations from particular studies performed in different parts of the world at different times may be erroneous due to spatial and temporal variability (Foster 1990, Underwood \& Petraitis 1993). Comparisons are often difficult due to variable experimental designs and different degrees of spatial replication. Even in the case of equivalent designs, variability in time and space may preclude any comparison (including qualitative comparisons) of studies performed at single distant localities at different times. Different localities within the same shore, although only a few kilometres apart, may differ, and usually they do, in average orientation, slope, wave exposure and intensity of recruitment. Consequently, both density and composition of the grazer assemblage as well as abundance and growth rates of algae may differ among close locations; hence the relative importance of grazing as a structuring agent. The practical implication is that to cope with this expected variability, any large scale comparison among shores must include replication at different spatial scales, from metres to kilometres, and temporal replication at different time scales. Recent examples of studies with adequate spatial replication can be found in Benedetti-Cecchi et al. (2000) and Boaventura et al. (2002), the former also with proper temporal replication.

It is obvious that not all species in the grazer assemblage have the same effect on algae (Underwood \& Jernakoff 1981, Underwood 1984). Often, this is the consequence of a single species or a reduced group of species having a disproportionate effect. Limpets are very often the key grazers in mid- and high tidal levels (Hawkins et al. 1992). In different parts of the world, other gastropods (Cervin \& Åberg 1997, Viejo et al. 1999), chitons (Dethier \&Duggins 1984) or even insect larvae (Robles \& Cubit 1981) may play relevant roles.

The aim of this work was to assess the role of dominant grazers (limpets) on the structure of species assemblages in mid-tidal levels of northern Spain at different spatial and temporal scales. Barnacles are the main space occupiers, in some zones covering up to more than $90 \%$ of available rock surface. Virtually no macroalgae are present and the grazer assemblage is limited to a small number of species (Anadón 1983). Structurally, the system is similar to those found in other parts of the world at the same tidal level (Stephenson \& Stephenson 1972, Raffaelli \& Hawkins 1996). The experimental design was intended to make broad comparisons of the role of grazers in high and mid-tidal levels on European shores. The experimental design considered temporal and spatial variability at 2 different scales: among and within seasons, and among and within localities. Within the framework of an international project (Chelazzi et al. 1998a), identical studies were performed on other European shores with the same experimental design at the same dates: Sweden (Lindegarth et al. 2001), Isle of Man, southern England and southern Portugal. Similar species assemblages but contrasting environmental conditions were identified in different locations, such as the Isle of Man, southern England and northern Spain. In other cases, both environmental conditions and species differed (e.g. Sweden and northern Spain).

\section{MATERIALS AND METHODS}

Localities and species. The study was carried out from May 1996 to October 1998 in 2 localities on the north shore of Spain, Campiello $\left(43^{\circ} 33^{\prime} \mathrm{N}, 6^{\circ} 24^{\prime} \mathrm{W}\right)$ and Artedo $\left(43^{\circ} 34^{\prime} \mathrm{N}, 6^{\circ} 12^{\prime} \mathrm{W}\right)$. Both localities are moderately exposed to wave action and have a gently sloping rock platform with many boulders. The rock platform in Campiello faces north and is slightly more exposed than in Artedo, which faces east. The nature 
of the rock is the same in both localities, largely quartzite with some veins of slate. The maximum tidal range of spring tides is around $4.3 \mathrm{~m}$. Intertidal communities are very similar in the 2 localities and have been described elsewhere (Anadón \& Niell 1981, Anadón 1983, Arrontes 1993). Briefly, the high shore between roughly 3 and $1.5 \mathrm{~m}$ above Lowest Astronomical Tide (LAT) is dominated by barnacles and grazing gastropods. Primary space is largely occupied by 2 species of barnacles, Chthamalus montagui and $C$. stellatus, small patches of the lichen Lichyna pygmaea and ephemeral blue green algae. Two species of limpets, Patella depressa and $P$. vulgata, coexist in this zone. The relative abundance of both species varies in the tidal range and along the shore. Other grazers are trochids (Gibbula spp. and Monodonta lineata) and small littorinids (species of the Littorina saxatilis group and Melaraphe neritoides). In both localities, the predatory whelk Thais (= Nucella) lapillus is present at low densities. Below the grazer-dominated zone, between 1.5 and $0.75 \mathrm{~m}$ above LAT, fucoids monopolise the space (Fucus vesiculosus and F. serratus in Campiello but only $F$. vesiculosus in Artedo). The lower tidal levels are dominated by Bifurcaria bifurcata, Chondrus crispus and Himanthalia elongata (the latter only in Artedo).

Experimental design. Three grazing treatments were considered. Limpets were removed and excluded from $50 \times 50 \mathrm{~cm}$ quadrats, hereafter named exclusion quadrats (E), using fences $5 \mathrm{~cm}$ high made of plastic coated iron mesh (with a mesh size of $1 \mathrm{~cm}$ ) attached to the rock with stainless steel screws and plastic plugs. Where the fences did not exactly fit the substratum, strips of artificial grass were introduced between the rock and the mesh to prevent small limpets passing under the fences. Artefacts might occur because of alterations of water flow within the exclusion quadrats or increased shading and wetness of the rock surface. Procedural controls (PC) to test for potential artefacts due to barriers consisted of partial fences. Quadrats were fenced at the corners, leaving an open space of $25 \mathrm{~cm}$ in the middle of each side. At several randomly chosen corners, strips of artificial grass were incorporated. Limpets could move freely in and out of the quadrats. The environmental conditions in the quadrats were more similar to those within the exclusion quadrats than to those on natural surfaces (but see comments and criticism on partial barriers as procedural controls by Johnson [1992] and Benedetti-Cecchi \& Cinelli [1997]). Finally, control quadrats (C) were marked with 2 screws on opposite corners and left otherwise untouched.

To cope with spatial heterogeneity, the experiment was replicated in 2 localities (Campiello and Artedo). Within each locality, the grazing treatments were replicated at different sites. At the lower part of the barnacle-dominated zone, 8 experimental sites interspersed along the intertidal platforms in Artedo and 8 in Campiello were selected in late May 1996, before the start of the experimental manipulations. Sites were around $15 \mathrm{~m}$ long, at least $30 \mathrm{~m}$ apart and had enough positions to install nine $50 \times 50 \mathrm{~cm}$ experimental quadrats (see below). Criteria for the selection of the quadrats were (1) an inclination between 0 and $45^{\circ}$, (2) simple topography and absence of large cracks, crevices or pools, (3) cover of barnacles (Chthamalus spp.) above $40 \%$, (4) being at least $1 \mathrm{~m}$ apart from the nearest quadrat and (5) absence of perennial macroalgae and less than $5 \%$ cover of ephemerals. No distinction between stable bedrock and large boulders was made. Temporal variability also considered 2 scales, start season (summer and winter) and 2 start dates within each season, which were different for each locality. Summer start dates were each of the 4 consecutive spring tides in June-July 1996. Two start dates were randomly assigned to each locality. Winter start dates were the 4 spring tides in December 1996-January 1997.

At each locality and date, 2 sites of the 8 previously selected were randomly chosen and 3 replicates of each grazing treatment were randomly allocated to each of the 9 quadrats previously selected at each site. The experiment involved a total of 144 quadrats ( 2 localities $\times 2$ seasons $\times 2$ start dates $\times 2$ sites $\times 3$ grazing treatments $\times 3$ replicates). With this design, experimental factors include grazing treatment $(G$, fixed) with 3 levels (E, PC and C), locality (L, random) with 2 levels (Campiello and Artedo), season (Se, fixed) with 2 levels (summer and winter), start date ( $D$, random), nested in the interaction $\mathrm{L} \times \mathrm{Se}$ and with 2 start dates per locality and season, and site ( $\mathrm{Si}$, random), nested in date and with 2 sites per date at each locality and season.

Two hypotheses were derived from the general model that limpets influence the structure of assemblages: (1) algal cover increases in exclusion quadrats when compared with both types of controls $(\mathrm{C}=\mathrm{PC}<\mathrm{E})$ and (2) barnacle cover decreases in exclusion quadrats when compared with controls $(\mathrm{C}=\mathrm{PC}>\mathrm{E})$. The undesirable effect of fences is analysed by testing the hypothesis that controls differ $(\mathrm{C} \neq \mathrm{PC})$, both for algae and barnacle cover. Temporal variability in the effect of limpet removal may be detected after significant tests for the interactions of grazing with season $(G \times$ Se) and grazing with date $[\mathrm{G} \times \mathrm{D}(\mathrm{Se} \times \mathrm{L})]$. The spatial heterogeneity may be detected after significant tests for the interactions of grazing with locality $(G \times L)$ and grazing with site $\{\mathrm{G} \times \mathrm{Si}[\mathrm{D}(\mathrm{Se} \times \mathrm{L})]\}$. Because the remaining terms in the model were not directly related to the hypotheses, they were ignored in the 'Discussion'. 
Height above LAT, orientation and slope were recorded for each quadrat. In addition, an estimation of roughness of the quadrats was obtained by loosely laying a thin chain with $4 \mathrm{~mm}$ links on the 2 diagonals. The excess in length of the sum of the 2 diagonals estimated with the chain in relation to the sum of the true diagonals of a $50 \times 50 \mathrm{~cm}$ quadrat was considered an estimate of the roughness of the rock.

Sampling. The experiment ran from June 1996 to January 1998. Proportions of Patella vulgata and $P$. depressa were estimated at the start of manipulations from animals removed from a variable number of exclusion quadrats in each locality. Quadrats were sampled during low spring tides with the point method using a grid made of double thread to avoid parallax errors and with 49 regularly spaced points. Samples were taken at the time of the manipulations, 15 d later, once a month during the first 3 months and then every 3 months until January 1998. To follow up colonisation by Fucus spp., its cover in exclusion quadrats was sampled on 2 additional dates, March and October 1998. Primary and secondary cover of all organisms present in the quadrats was recorded and transformed to percentages. Present but not recorded organisms were assigned a cover of $1 \%$. When possible, organisms were identified to species in the field, though some taxonomically difficult groups were always assigned to higher categories (e.g. Ceramiales). The number of trochids and limpets, with no distinction of species, was also recorded. Limpets entering the exclusion quadrats were counted and removed.

Data analysis. Hypotheses were tested using analysis of variance (ANOVA). The existence of artefacts was tested using a priori comparisons (Underwood 1997). After significant tests, effects involving grazing, either as a main effect or in interaction, were split into 2 comparisons: Among Controls (i.e. PC vs C) and Exclusion vs Controls. The former tested for experimental artefacts, while the latter tested for effect of limpet removal. In some cases, artefacts might exist (see 'Results') and therefore to estimate the effect of limpets we compared Exclusion and Procedural Control quadrats. Comparisons were not non-independent and non-orthogonal and therefore the probability of Type I error was increased. However, we kept $\alpha=0.05$ for each comparison to avoid excessive Type II errors (Underwood 1997). Algal species were pooled in 2 groups: (1) Fucus spp. distinguishing between primary and secondary cover, and (2) all other macroalgae pooled (only primary cover). For cover of algae, the analysed data were percentage of cover in individual quadrats. For barnacles, because cover at any date is dependent on cover at the beginning of the experiment, the analysed data were proportions of change in cover in individual quadrats $[100 \times$ (initial cover final cover)/initial cover]. Apart from analyses on the effect of limpet removal on the global assemblage of algae and barnacles, additional analyses tested the success of fences in excluding limpets and variations in the abundance of trochids.

With this design, tests for grazing as a main effect and some tests for interaction had a reduced power (df $=2,2$ ). Different experimental designs might provide more powerful tests for these factors, but the work reported here was part of a larger experiment and therefore constrained by the need for a common design (Chelazzi et al. 1998a). We pooled non-significant interactions $(p>0.25)$ involving random factors to increase the power of the tests involving the grazing treatment. The sequential decision pooling procedure described in Winer (1971) was used. Preliminary tests were performed to check if the interaction Grazing $\times$ Date could be eliminated from the model and pooled with Grazing $\times$ Site. Then, we tested the significance of Grazing $\times$ Locality $\times$ Season and Grazing $\times$ Locality against the pooled error term. If not significant, the tests for Grazing $\times$ Season and Grazing against the new pooled error term would have considerably increased the power ( $\mathrm{df}=2,28)$. Cochran's test was used to test for heterogeneity of variances. When required, data were transformed to meet the assumption of homogeneity of variance.

The relationship between the proportion of Fucus cover and height on the shore as well as the effects of locality (random factor) and season (fixed) were fitted by a logistic regression using the SAS Macro program GLIMMIX, which iteratively uses the SAS MIXED procedure (SAS 1996). The MIXED procedure implements a generalisation of the standard linear model that allows for proper incorporation of random effects. Model parameter estimates were fitted using the restricted maximum likelihood method (Litell et al. 1996). For further details on the MIXED procedure, see Litell et al. (1996) and SAS (1996).

There is a problem of confounding effects associated with comparisons of means of treatments started in different seasons. For instance, in January 1998, differences between quadrats established in summer and those established in winter could be due to different start seasons as much as to the different time during which the changes occurred (an average of 18 mo for summer quadrats and 12 mo for winter quadrats). On the other hand, if means are compared after a fixed time from establishment of experimental quadrats (e.g. $12 \mathrm{mo}$ ), then differences could be due to the fact that quadrats were sampled at different times of the year (summer for summer quadrats and winter for winter quadrats). If in the first case significant seasonal effects might be due to the time elapsed since the experi- 
mental manipulations, in the second, seasonal effects could be due to differences in the presence or abundance of species at different times of the year. As this problem is unavoidable with the present design, data were analysed 12 mo after the establishment of the quadrats and at the end of the experiment, and a cautious interpretation of the results was made. In other cases, analyses were performed with data at the time in which maximum abundance was recorded. Temporal trends were deduced from visual inspection of graphs.

\section{RESULTS}

\section{Initial conditions}

Initial cover of barnacles was very variable and varied between 41 and 96\%. Significant differences existed among sites (Table 1A). The triple interaction (Grazing $\times$ Locality $\times$ Season) was also significant. The height on the shore of experimental quadrats oscillated between 1.17 and $2.64 \mathrm{~m}$ above LAT. Despite this wide range of variation, only significant differences in tidal height were detected among sites (Table 1A). ANOVA revealed no significant main effects or interactions, with associated $\mathrm{p}$ always above 0.3. No correlation existed between the height on the shore of the experimental quadrats and barnacle cover $(r=0.063, p>$
0.05). Slope and roughness of experimental quadrats did not differ among any combination of treatments (no significant effects in ANOVA, data not shown). While orientations were not statistically analysed, no obvious trend was observed for quadrats under any treatment. In Campiello, relative abundances of limpets at the start of the experiment were 81.2 and $18.8 \%(\mathrm{~N}=1267)$ for Patella depressa and P. vulgata respectively. The mean size (SE) was $1.46 \pm 0.012 \mathrm{~cm}(\mathrm{~N}=1029)$ for $P$. depressa and $1.53 \pm 0.035 \mathrm{~cm}(\mathrm{~N}=238)$ for $P$. vulgata. In Artedo, relative abundances of limpets were 90.3 and $9.7 \%(\mathrm{~N}=859)$ for $P$. depressa and $P$. vulgata respectively, and the mean sizes were $1.51 \pm 0.018 \mathrm{~cm}$ $(\mathrm{N}=776)$ and $1.47 \pm 0.076 \mathrm{~cm}(\mathrm{~N}=83)$ respectively. Data on the density of limpets in some quadrats before manipulations were lost and thus, the initial density of limpets was estimated from untouched controls at the time of the first sampling. Initial densities were $59.13 \pm$ 4.42 (mean $\pm \mathrm{SE}, \mathrm{N}=24$ ) for Campiello and $42.5 \pm 3.59$ for Artedo. ANOVA revealed that differences in mean density were significant only between sites within each date, locality and season (Table 1B).

\section{Effects of limpet removal}

Fences failed to completely exclude limpets in exclusion quadrats (Fig. 1A); however, the density of limpets was considerably lower in exclusion quadrats

Table 1. Analysis of differences in initial conditions of experimental quadrats. (A) Barnacle cover and tidal height. For cover of barnacles, variances were homogeneous after arcsine transformation. No transformation was needed for height on the shore. (B) Density of limpets in unfenced control quadrats. No transformation needed (ns $=$ non-significant, ${ }^{*} p<0.05,{ }^{* * *} p<0.001$ ). Because the analyses were performed to identify gross differences in initial conditions, pooling was not necessary

\begin{tabular}{|c|c|c|c|c|c|c|c|c|c|}
\hline & Source of variation & df & Error term & MS & $F$ & $\mathrm{p}$ & MS & $F$ & $\mathrm{p}$ \\
\hline \multicolumn{4}{|c|}{ (A) Barnacles and tidal height } & \multicolumn{3}{|c|}{ Barnacles } & \multicolumn{3}{|c|}{ — Tidal height } \\
\hline (a) & Grazing $=\mathrm{G}$ & 2 & (d) & 77.18 & 1.09 & ns & 0.033 & 0.62 & ns \\
\hline (b) & Locality = L & 1 & (h) & 1142.88 & 4.68 & ns & 0.030 & 0.07 & ns \\
\hline (c) & Season $=\mathrm{Se}$ & 1 & (f) & 238.97 & 0.28 & ns & 0.021 & 0.05 & ns \\
\hline (d) & $\mathrm{G} \times \mathrm{L}$ & 2 & (i) & 71.10 & 3.23 & $\mathrm{~ns}$ & 0.054 & 0.99 & $\mathrm{~ns}$ \\
\hline (e) & $\mathrm{G} \times \mathrm{Se}$ & 2 & (g) & 10.47 & 0.09 & ns & 0.010 & 0.19 & ns \\
\hline (f) & $\mathrm{L} \times \mathrm{Se}$ & 1 & (h) & 855.84 & 3.51 & ns & 0.427 & 0.96 & $\mathrm{~ns}$ \\
\hline (g) & $\mathrm{G} \times \mathrm{L} \times \mathrm{Se}$ & 2 & (i) & 117.87 & 5.36 & $*$ & 0.054 & 0.99 & ns \\
\hline (h) & Date $=\mathrm{D}(\mathrm{L} \times \mathrm{Se})$ & 4 & (j) & 243.99 & 1.11 & ns & 0.446 & 1.46 & ns \\
\hline (i) & $\mathrm{G} \times \mathrm{D}(\mathrm{L} \times \mathrm{Se})$ & 8 & $(\mathrm{k})$ & 21.98 & 0.29 & ns & 0.055 & 0.98 & ns \\
\hline (j) & Site $=\operatorname{Si}[D(L \times$ Se $)]$ & 8 & (l) & 219.80 & 5.01 & $* * *$ & 0.306 & 4.65 & $* * *$ \\
\hline (k) & $\mathrm{G} \times \mathrm{Si}[\mathrm{D}(\mathrm{L} \times \mathrm{Se})]$ & 16 & (l) & 75.85 & 1.73 & ns & 0.056 & 0.85 & ns \\
\hline (l) & Residual & 96 & & 43.88 & & & 0.066 & & \\
\hline \multicolumn{10}{|c|}{ (B) Limpets } \\
\hline (a) & Locality = L & 1 & (d) & 3316.69 & 2.59 & ns & & & \\
\hline (b) & Season $=\mathrm{Se}$ & 1 & (c) & 165.02 & 0.19 & ns & & & \\
\hline (c) & $\mathrm{L} \times \mathrm{Se}$ & 1 & (d) & 858.62 & 0.67 & ns & & & \\
\hline (d) & Date $(\mathrm{L} \times \mathrm{Se})$ & 4 & (e) & 1281.06 & 2.03 & ns & & & \\
\hline (e) & $\operatorname{Site}[\mathrm{D}(\mathrm{L} \times \mathrm{Se})]$ & 8 & (f) & 630.85 & 3.01 & ${ }^{*}$ & & & \\
\hline (f) & Residual & 32 & & 209.50 & & & & & \\
\hline
\end{tabular}


than in the controls. Most of the limpets found within the fences were of small size and their numbers followed seasonal variations in abundance in control quadrats (data not shown). The number of limpets in exclusion quadrats exhibited an increased trend towards the end of the experiment, possibly reflecting damage to the fences and previously unnoticed recruitment. At the time of highest abundance of limpets (May 1997), differences existed between exclusion and procedural control quadrats, but also between both types of control quadrats (Fig. 1A). Average density was higher in procedural controls than in untouched control quadrats. Apparently, fences attracted limpets. Large differences among sites are also evident in Fig. 1A. ANOVA revealed that the effects of grazing and site were significant (Table 2). Analyses performed 3, 6 and 12 mo after manipulations (data not shown) rendered similar results, though the interaction Grazing $\times$ Site was also significant. Because the number of limpets in exclusion quadrats was fairly constant across sites, this signifi- cant interaction reflected differences in the pooled abundance in both types of controls.

At the time of highest density (November 1997), trochids were more abundant in exclusion quadrats than in controls (Fig. 1B). On some sampling dates (summer months, data not shown) virtually no animals were found in control quadrats, while they were still present in exclusion quadrats. Large differences in density also existed between sites. ANOVA was performed for data collected in November 1997 (Table 2). Apart from the significant site effects, the analysis revealed significant differences between exclusion quadrats and controls. No significant differences existed between the 2 types of controls, though a trend of larger density in the procedural control quadrats as compared to untouched controls was observed. In fact, if ANOVA was exclusively performed with control quadrats (data not shown), a significant difference between the 2 types of controls existed. As in the case for limpets, trochids appeared to be attracted by fences.
A. Limpets

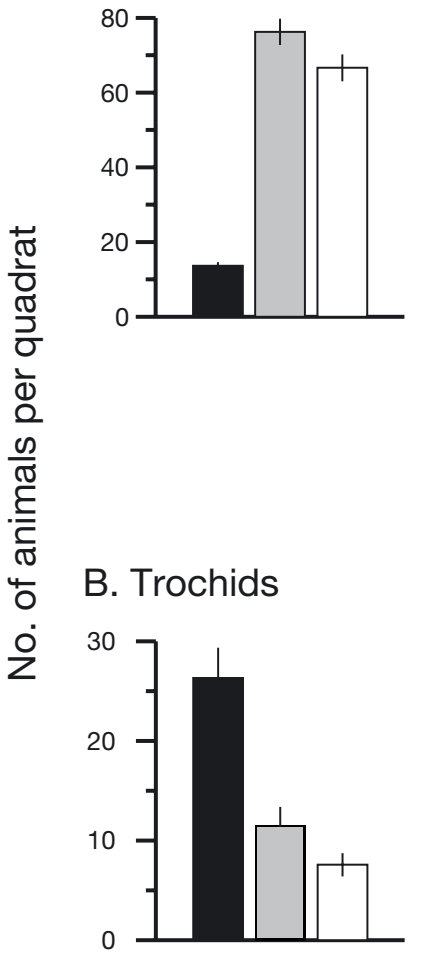

Exclusion

Procedural Control Control
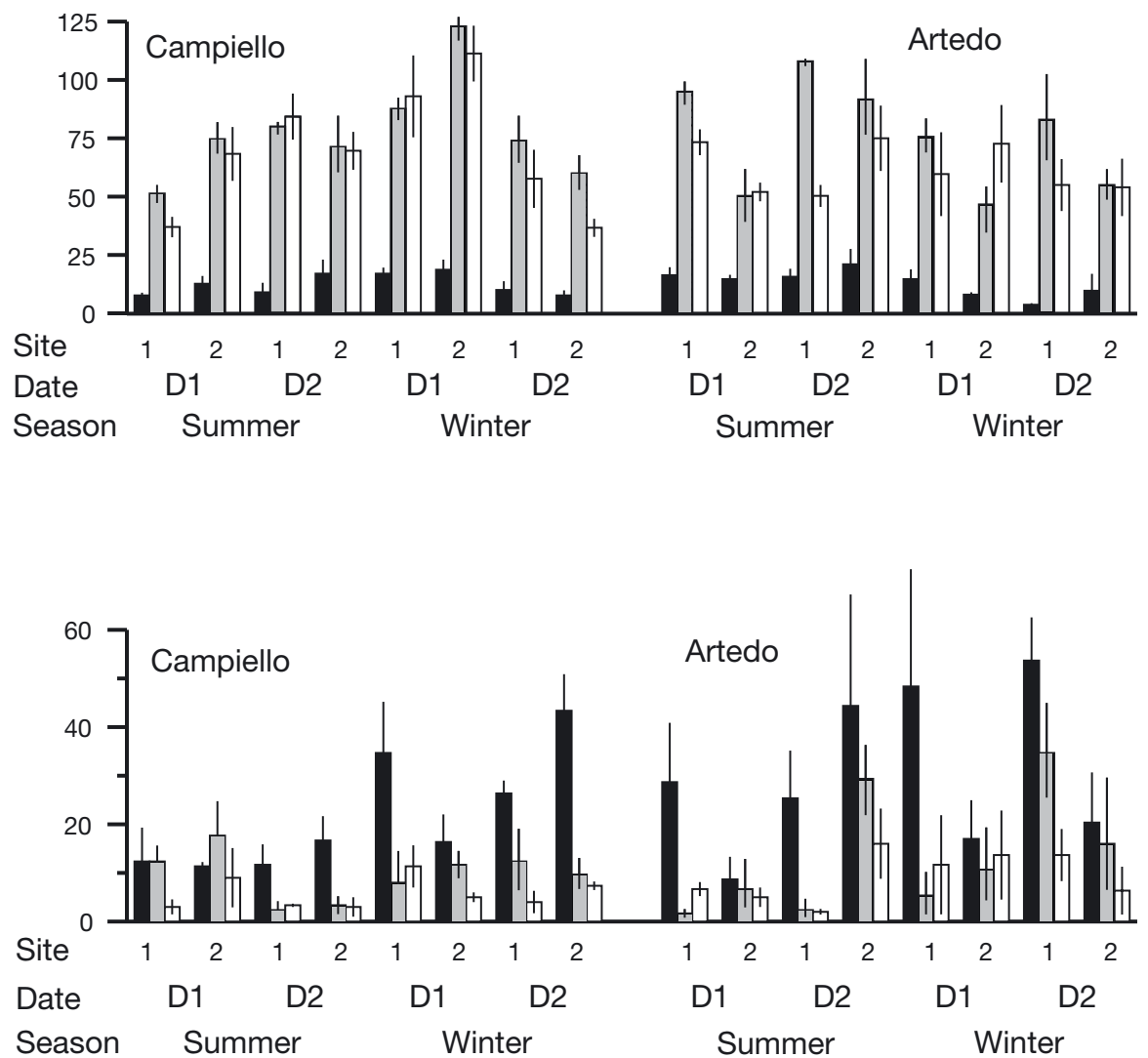

Fig. 1. Mean abundance of (A) limpets in the 3 grazing treatments in May 1997 and (B) trochids in November 1997. Left panels are data from all sites pooled $(\mathrm{N}=48)$. Right panels are abundance at individual sites. In all cases, data are mean $\pm \mathrm{SE}$ 
Table 2. Analysis of differences in density of limpets (May 97) and Trochids (Nov 97). Variances were homogeneous after square root transformation. In both cases, the value for 1 control quadrat lost in Artedo was replaced by the mean of the remaining 2 quadrats of the same treatment and site, and $1 \mathrm{df}$ subtracted from the residual (ns = non-significant, ${ }^{*} \mathrm{p}<0.05,{ }^{* * *} \mathrm{p}<0.001$ )

\begin{tabular}{|c|c|c|c|c|c|c|c|c|c|}
\hline & \multirow{2}{*}{$\begin{array}{l}\text { Source of } \\
\text { variation }\end{array}$} & \multirow[t]{2}{*}{$\mathrm{df}$} & \multirow{2}{*}{$\begin{array}{l}\text { Error } \\
\text { term }\end{array}$} & \multicolumn{3}{|c|}{ — Limpets } & \multicolumn{3}{|c|}{ —Trochids } \\
\hline & & & & MS & $F$ & $\mathrm{p}$ & MS & $F$ & $\mathrm{p}$ \\
\hline \multirow[t]{3}{*}{ (a) } & Grazing = G & 2 & & 364.01 & & & 77.09 & & \\
\hline & $\begin{array}{l}\text { Exclusion vs } \\
\text { procedural control }\end{array}$ & 1 & Pooled-2 & 609.34 & 360.25 & $* * *$ & 94.15 & 35.22 & *** \\
\hline & Among controls & 1 & Pooled-2 & 8.45 & 5.00 & * & 3.45 & $\begin{array}{r}1.29 \\
1.29\end{array}$ & ns \\
\hline (b) & Locality = L & 1 & (h) & 0.55 & 0.05 & ns & 5.13 & 0.83 & ns \\
\hline (c) & Season $=\mathrm{Se}$ & 1 & (f) & 0.24 & 0.01 & ns & 23.72 & 50.62 & ns \\
\hline (d) & $\mathrm{G} \times \mathrm{L}$ & 2 & Pooled-1 & 1.22 & 0.38 & ns & 1.48 & 0.52 & ns \\
\hline (e) & $\mathrm{G} \times \mathrm{Se}$ & 2 & Pooled-2 & 0.62 & 0.37 & ns & 2.23 & 0.83 & ns \\
\hline (f) & $\mathrm{L} \times \mathrm{Se}$ & 1 & (h) & 20.78 & 1.90 & ns & 0.47 & 0.08 & ns \\
\hline (g) & $\mathrm{G} \times \mathrm{L} \times \mathrm{Se}$ & 2 & Pooled-1 & 2.38 & 1.42 & ns & 1.94 & 0.68 & ns \\
\hline (h) & Date $=\mathrm{D}(\mathrm{L} \times \mathrm{Se})$ & 4 & (j) & 10.95 & 3.71 & ns & 6.18 & 0.69 & ns \\
\hline (i) & $\mathrm{G} \times \mathrm{D}(\mathrm{L} \times \mathrm{Se})$ & 8 & $(\mathrm{k})$ & 1.92 & 1.24 & ns & 3.54 & 1.42 & ns \\
\hline (j) & Site $=\operatorname{Si}[D(L \times S e)]$ & 8 & (l) & 2.95 & 2.56 & * & 9.01 & 3.38 & $*$ \\
\hline (k) & $\mathrm{G} \times \mathrm{Si}[\mathrm{D}(\mathrm{L} \times \mathrm{Se})]$ & 16 & (l) & 1.55 & 1.34 & ns & 2.48 & 0.93 & ns \\
\hline \multirow[t]{3}{*}{ (l) } & Residual & 95 & & 1.15 & & & 2.66 & & \\
\hline & Pooled-1 error term: (i) + (k) & 24 & & 1.67 & & & 2.83 & & \\
\hline & Pooled-2 error term: $(\mathrm{d})+(\mathrm{g})+(\mathrm{i})+(\mathrm{k})$ & 28 & & 1.69 & & & 2.67 & & \\
\hline
\end{tabular}

\section{Effect of limpet removal on macroalgae}

The most abundant algal species in exclusion quadrats were Fucus spp. One year after manipulation, several quadrats exhibited a secondary cover above $95 \%$. Although all specimens that could be safely identified were F. vesiculosus, many small specimens remained unidentified and we chose to keep the generic denomination. Except for 1 site in Artedo, in which Fucus colonised both types of control quadrats, measurable cover of Fucus only appeared in exclusion quadrats (Fig. 2). Only these quadrats were analysed for differences in cover. The analysis is simplified by dropping the main effect of grazing and its interactions from the model and testing for spatial and temporal effects on the growth of Fucus in exclusion quadrats. There were problems with analyses of cover of Fucus. Even after transformation of data, heterogeneity of variances and gross departures from normality existed for some of the sampling dates. Lack of normality was a consequence of obvious bimodality of data within the exclusion treatment, with a fraction of the quadrats lacking measurable cover of Fucus and a fraction with large secondary covers. The analyses were made anyway and therefore their results must be used to suggest possible trends rather than to construct unambiguous conclusions. However, non-parametric analyses of variance were performed where clear bimodal data existed (DISTLM v.2, Anderson 2001, 2003, McArdle \& Anderson 2001). F-ratios and associated probabilities were almost identical to those obtained with parametric ANOVAs (data not shown) and therefore, it is concluded that departure from normality had little effect. Early colonisation, estimated as increases in primary cover, varied between localities and seasons (significant interaction in ANOVA for primary cover, Table 3). Colonisation was very rapid in Artedo in summer quadrats and similar in both seasons in Campiello, and in Artedo in winter (Fig. 2). No other effect was significant. Twelve months after manipulation, ANOVA revealed that the only significant effect was site. As shown in Fig. 3, sites within the same time period, locality and season exhibited large differences in average cover (e.g. more than $80 \%$ and less than $10 \%$ for sites on one winter date in Artedo). Although mean secondary cover appeared to be higher in summer than in winter quadrats (Fig. 2), no effect of season was detected. In January 1998, with quadrats being 18 and 12 mo old, the results of ANOVA were identical (data not shown). In October 1998, angular transformation rendered homogeneous variances and almost no bimodal distribution. Again, ANOVA revealed that site was the only significant effect. This result suggests that trends inferred from previous analyses may be close to reality. However, differences among sites were smaller (Fig. 3).

Colonisation by Fucus was influenced by the height on the shore of individual quadrats. More Fucus appeared in lower than in higher quadrats (Fig. 4, Table 4). No effect of locality existed but summer quadrats were significantly affected by height.

Excluding Fucus spp., a total of 27 taxa of algae were identified in the experimental quadrats. Their relative abundance was estimated as the percentage of the 

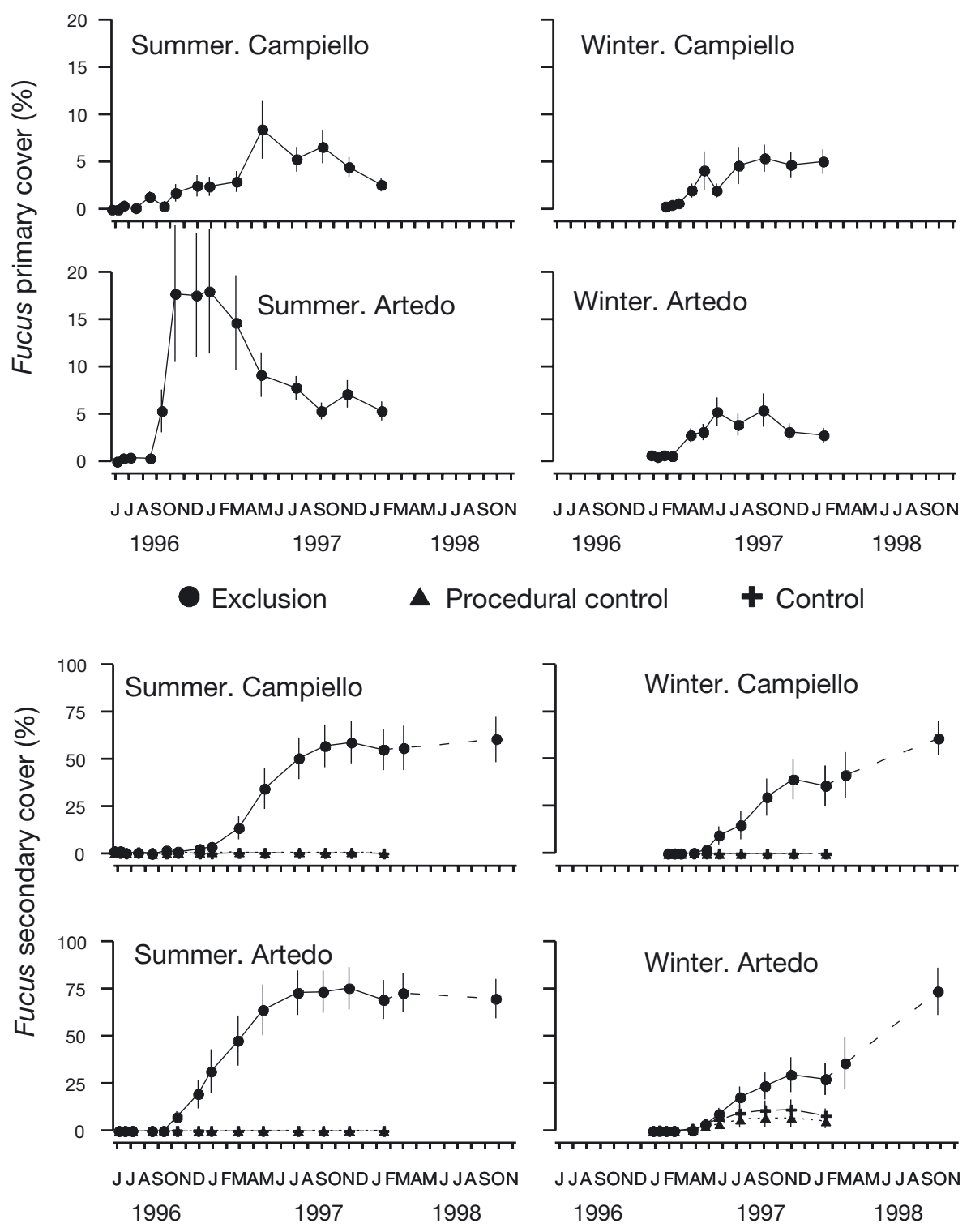

Fig. 2. Fucus spp. Changes in cover. Top panels: primary cover in exclusion quadrats alone. Bottom panels: secondary cover. Exclusion quadrats were sampled for secondary cover on 2 additional dates, March and October 1998. In all cases, data are mean $\pm \mathrm{SE}(\mathrm{N}=12)$

Table 3. Analysis of differences in Fucus cover. Primary cover was analysed 6 mo after manipulation. Variances were still heterogeneous (Cochran's $C=0.36,0.01<\mathrm{p}<0.05$ ) after arcsine transformation. For analyses of secondary cover, arcsine transformation rendered homogeneous variances though gross departure from normality occurred 12 mo after manipulations. For October 1998, variances were homogeneous and close to normality after arcsine transformation $\left(\mathrm{ns}=\mathrm{non}-\right.$ significant, ${ }^{*} \mathrm{p}<0.05$, $\left.{ }^{* *} \mathrm{p}<0.01\right)$. Pooling of non-significant error terms did not alter the significance of tests for locality, season and their interaction, and is not presented

\begin{tabular}{|c|c|c|c|c|c|c|c|c|c|c|c|c|}
\hline & \multirow{3}{*}{$\begin{array}{l}\text { Source of } \\
\text { variation }\end{array}$} & \multirow[t]{3}{*}{ df } & \multirow{3}{*}{$\begin{array}{l}\text { Error } \\
\text { term }\end{array}$} & \multicolumn{3}{|c|}{ Primary } & \multicolumn{6}{|c|}{ Secondary } \\
\hline & & & & & $-6 \mathrm{mo}$ & - & & $12 \mathrm{mo}$ & - & & Oct 9 & - \\
\hline & & & & MS & $F$ & $\mathrm{p}$ & MS & F & $\mathrm{p}$ & MS & $F$ & $\mathrm{p}$ \\
\hline (a) & Locality = L & 1 & (d) & 355.32 & 7.35 & ns & 406.53 & 0.49 & ns & 666.74 & 0.53 & ns \\
\hline (b) & Season $=\mathrm{Se}$ & 1 & (c) & 123.12 & 0.23 & ns & 6203.44 & 2.93 & ns & 152.32 & 6.25 & ns \\
\hline (c) & $\mathrm{L} \times \mathrm{Se}$ & 1 & (d) & 516.89 & 10.69 & $*$ & 2119.39 & 2.54 & ns & 24.39 & 0.02 & ns \\
\hline (d) & Date $(\mathrm{L} \times \mathrm{Se})$ & 4 & (e) & 48.38 & 0.21 & ns & 835.69 & 0.40 & ns & 1247.23 & 0.80 & ns \\
\hline (e) & $\operatorname{Site}[\mathrm{D}(\mathrm{L} \times \mathrm{Se})]$ & 8 & (f) & 223.43 & 2.02 & ns & 2083.85 & 3.83 & ${ }^{* *}$ & 1560.72 & 2.51 & $*$ \\
\hline (f) & Residual & 32 & & 110.63 & & & 543.99 & & & 621.53 & & \\
\hline
\end{tabular}




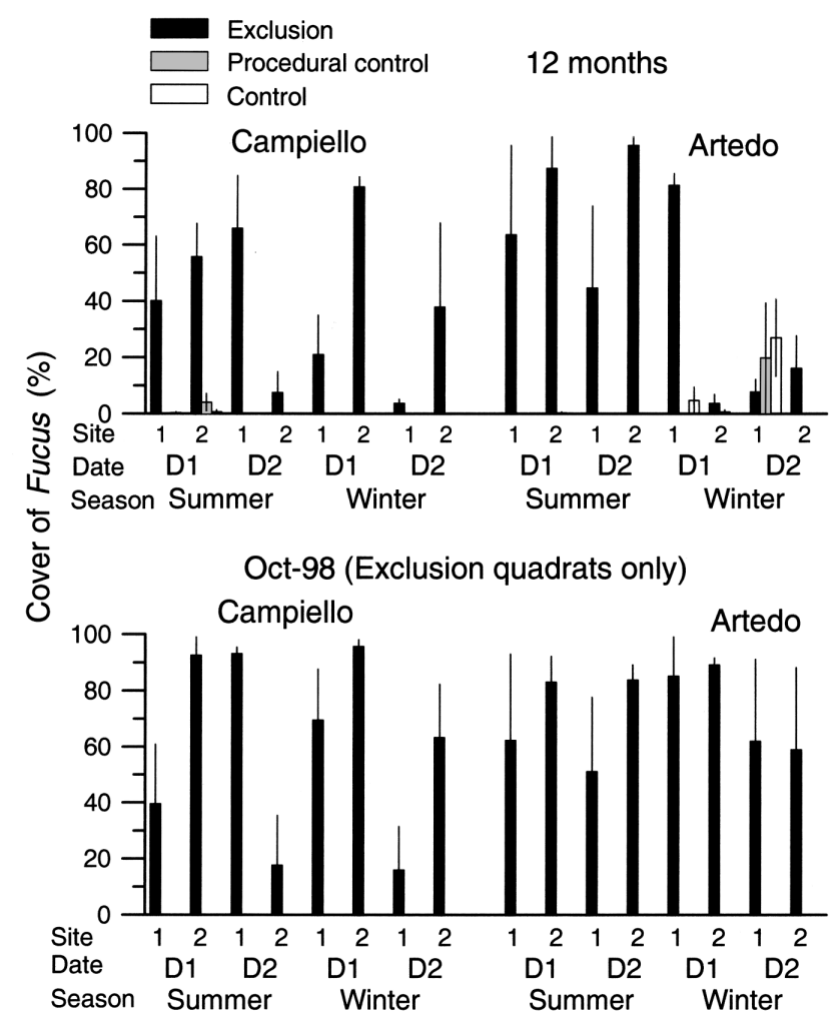

Fig. 3. Fucus spp. Mean secondary cover at individual sites 12 mo after the start of the experiment and in October 1998 (only exclusion quadrats). Data are mean $\pm \mathrm{SE}(\mathrm{N}=3)$

number of interceptions of individual taxa in relation to the total number of interceptions of all algae (Fucus excluded), in all quadrats, on all sampling dates. Most of the identified taxa were recorded sporadically. The soft encrusting species Ralfsia verrucosa and the bluegreen Rivularia bullata were the most abundant taxa and altogether comprised more than $75 \%$ of all observations. Groups with more than $1 \%$ of relative abundance of algae are presented in Fig. 5.

Measurable algal growth almost exclusively occurred in exclusion quadrats (Fig. 6) and therefore, only these were analysed for differences in algal cover. On the dates of highest abundance (May and October 1997 for summer and winter quadrats in Campiello, and November 1997 for both seasons in Artedo), the average percentage of cover varied between more than $40 \%$ in some sites to less than $5 \%$ in others (Fig. 6). The analysis was performed with data from these sampling dates. ANOVA revealed that only the site was significant (Table 5). Although important differences appeared to exist between summer quadrats in Campiello and Artedo, ANOVA failed to detect differ-

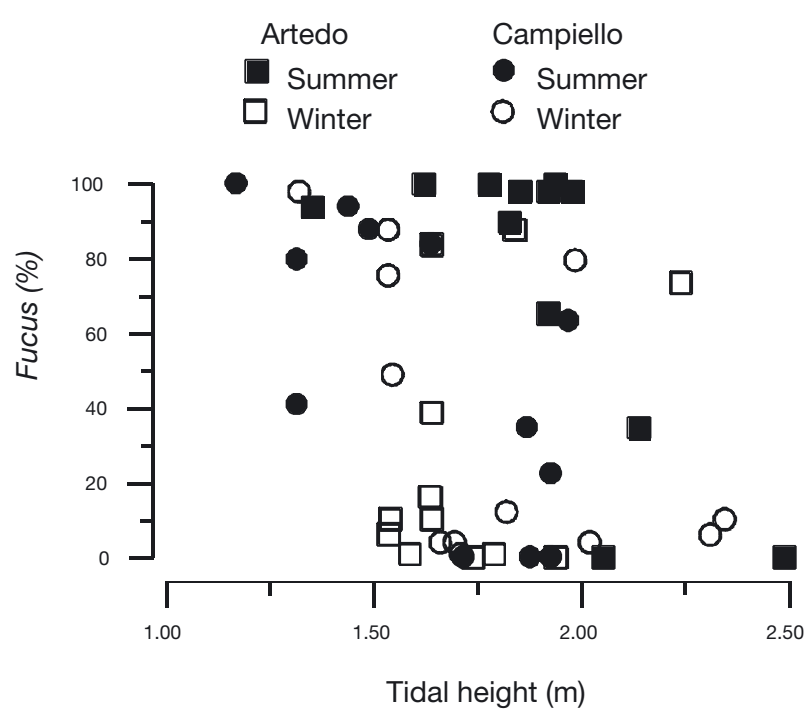

Fig. 4. Fucus spp. Relationship between secondary cover of individual exclusion quadrats 12 mo after the start of the experiment and height on the shore

ences; possibly due to the large site effect. The pattern of variation in abundance was similar for summer and winter quadrats in Campiello (Fig. 6). Highest cover was observed 10-11 mo after manipulations. In addition to low cover, no clear pattern was observed in summer quadrats in Artedo. It could be hypothesised that rapid growth of Fucus in these quadrats prevented growth of other algae.

\section{Effect of limpet removal on barnacles}

There was an overall trend of barnacles to decrease with time (Fig. 7). The decrease, however, was more marked in exclusion quadrats. Apparent differences also existed between seasons (more barnacles being lost in exclusion summer quadrats) and between sites within each date, locality and season. Data were analysed 12 mo after manipulations and in January

Table 4. Analysis of the relationship between the proportion of Fucus cover and height on the shore. Logistic regression using SAS GLIMMIX (SAS 1996)

\begin{tabular}{|lcccc|}
\hline & $\begin{array}{c}\text { Test of effects } \\
\text { Likelihood ratio test }\left(\chi^{2}\right)\end{array}$ & df & $p$ & $\begin{array}{c}\text { Parameter } \\
\text { estimates (SE) }\end{array}$ \\
\hline Location (random) & 0.60 & 1 & $>0.750$ & \\
& $F$-value & & & Summer: \\
Season (fixed) & 7.71 & 1,44 & 0.008 & $1.421(1.813)$ \\
Tidal height (fixed) & 5.52 & 1,44 & 0.023 & $-2.449(0.512)$ \\
Intercept & & & & $3.458(1.813)$ \\
\hline
\end{tabular}




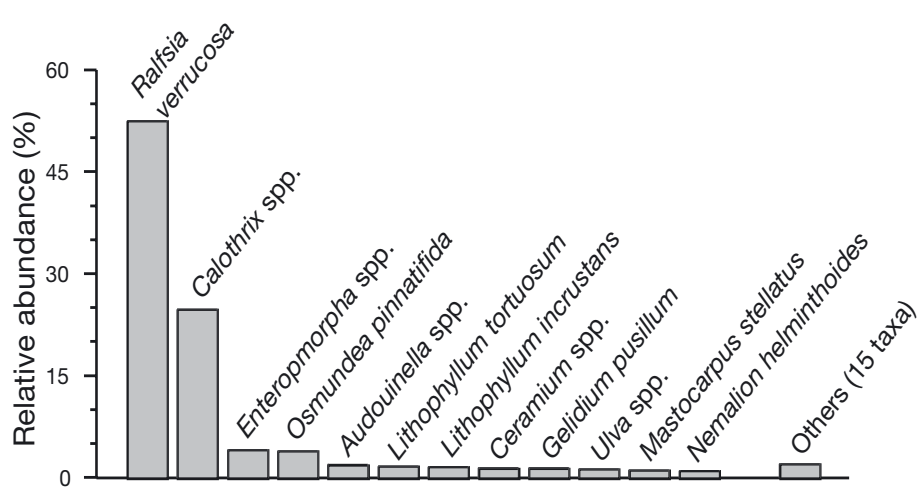

Fig. 5. Relative abundance of macroalgae (Fucus excluded) in all quadrats at all sampling dates (see text). Only taxa with a relative abundance above $1 \%$ are identified
1998. For this date, an additional analysis was performed with summer quadrats. After 12 mo, variances were still heterogeneous after angular transformation and the comment made for Fucus cover is applicable. Analyses for both 12 mo and January 1998 data revealed a significant main effect of grazing, with exclusion quadrats losing more barnacles than procedural controls and no differences among controls (Table 6A). This main effect, however, is not interpretable due to the significant interactions. The site and the more relevant interaction of grazing with the site were also significant. In some sites, but not in others, the removal of limpets led to a larger reduction of barnacles in relation to procedural controls. Both analyses also revealed that differences among controls existed. These differences were not consistent across sites and though there was a trend in some sites for procedural controls to lose more barnacles than untouched controls, in others, the opposite or no trend was observed. As for the density of limpets, the analyses suggested that some artefacts caused by fences might have occurred. Significant effects of locality existed for the 12 mo data, with more barnacles being lost in Campiello than in Artedo. For the January 1998 data, the interaction between grazing and season was significant, more barnacles being lost in exclusion than in controls treatments in quadrats established in summer, with a smaller difference in winter quadrats (Fig. 7). No significant interaction between differences among controls with seasons was detected. Loss of barnacles was also evident if only summer quadrats in January 1998 were considered (Fig. 7). ANOVA for these data rendered similar significant results (Table 6B), but no significant differences between controls were found.

Loss of barnacles due to the exclusion treatment was correlated with cover of Fucus of individual quadrats (Fig. 8). The proportion of barnacle cover lost 12 mo after manipulations was positively related to cover by Fucus ( $\mathrm{r}=0.523$, df $=46, \mathrm{p}<0.01)$. Note that an inverse relationship existed between height on the shore and the percentage of cover of Fucus. Similarly, loss of barnacles was also inversely related to height on the shore of the quadrats (data not shown, $\mathrm{r}=$

Fig. 6. Top panel: changes in the primary cover of macroalgae (Fucus excluded) during the experiment $(\mathrm{N}=12)$. Arrows indicate dates at which maximum cover was observed at each locality and season. These dates were used for ANOVA. Bottom panel: mean abundance of macroalgae at individual sites on the sampling dates with maximum cover $(\mathrm{N}=3)$. In all cases, data are mean $\pm \mathrm{SE}$ 
Table 5. Analysis of differences in cover by macroalgae (Fucus excluded). Only exclusion quadrats were analysed. Variances were homogeneous and data were not transformed (ns = non-significant, ${ }^{* * *} \mathrm{p}<0.001$ ). Pooling of non-significant error terms did not alter the significance of tests for locality, season and their interaction, and is not presented

\begin{tabular}{|c|c|c|c|c|c|c|}
\hline & $\begin{array}{l}\text { Source of } \\
\text { variation }\end{array}$ & df & $\begin{array}{l}\text { Error } \\
\text { term }\end{array}$ & MS & $F$ & $\mathrm{p}$ \\
\hline (a) & Locality = L & 1 & (d) & 1096.81 & 4.08 & ns \\
\hline (b) & Season $=\mathrm{Se}$ & 1 & (c) & 44.44 & 0.10 & ns \\
\hline (c) & $\mathrm{L} \times \mathrm{Se}$ & 1 & (d) & 455.70 & 1.69 & $\mathrm{~ns}$ \\
\hline (d) & Date $(\mathrm{L} \times \mathrm{Se})$ & 4 & (e) & 269.10 & 0.24 & ns \\
\hline (e) & $\operatorname{Site}[D(L \times S e)]$ & 8 & (f) & 1121.82 & 12.70 & $* * *$ \\
\hline (f) & Residual & 32 & & 88.33 & & \\
\hline
\end{tabular}

quadrats under each grazing treatment in which whelks were observed at least once is compared, whelks occurred more in exclusion than in control quadrats (Table 7). No significant differences were observed between controls. Data suggested a relationship between secondary cover of Fucus 18 mo after manipulation and the accumulated number of whelks counted in individual exclusion quadrats manipulated in summer (Fig. 9B). While at high covers of Fucus whelks were either fairly common or rare, at low covers whelks were always rare. There could also be a relationship between the accumulated number of whelks in exclusion quadrats and the proportion of barnacle cover lost (Fig. 9A). Again, while both a small or large proportion of cover could
$-0.370, \mathrm{df}=46, \mathrm{p}<0.05)$. For summer quadrats in January 1998 (18 mo old) the relationships still held (Fucus, $\mathrm{r}=0.712$, df $=22, \mathrm{p}<0.01$; height, $\mathrm{r}=-0.418$, df $=$ $22, \mathrm{p}<0.05)$.

The loss of barnacle cover may also be a consequence of another indirect effect. Specimens of the whelk Thais lapillus were occasionally found within the experimental quadrats. Occurrence was very irregular, whelks being observed in a low proportion of the visits to individual quadrats and, when present, in variable numbers, ranging from 1 to 37 specimens in 1 procedural control (Table 7). Although this observation precluded any formal statistical comparison of the effect of grazing manipulation as undertaken above, some exploratory description is possible. If all animals counted in all quadrats at all sampling dates under each grazing treatment are pooled, a trend can be observed (Fig. 9A, Table 7). More animals appeared in exclusion than in control quadrats. In addition, if data are pooled for 3 periods, 0 to 6,7 to 12 and 13 to 18 mo after manipulations, then it can be observed that differences became relevant in late sampling dates (Fig. 9A). If the number of individual

Fig. 7. Top panels: changes in barnacle cover $(\mathrm{N}=12)$. Bottom panels: losses in barnacle cover at individual sites 12 and 18 mo after the start of the experiment $(\mathrm{N}=3)$. In all cases, data are mean $\pm \mathrm{SE}$

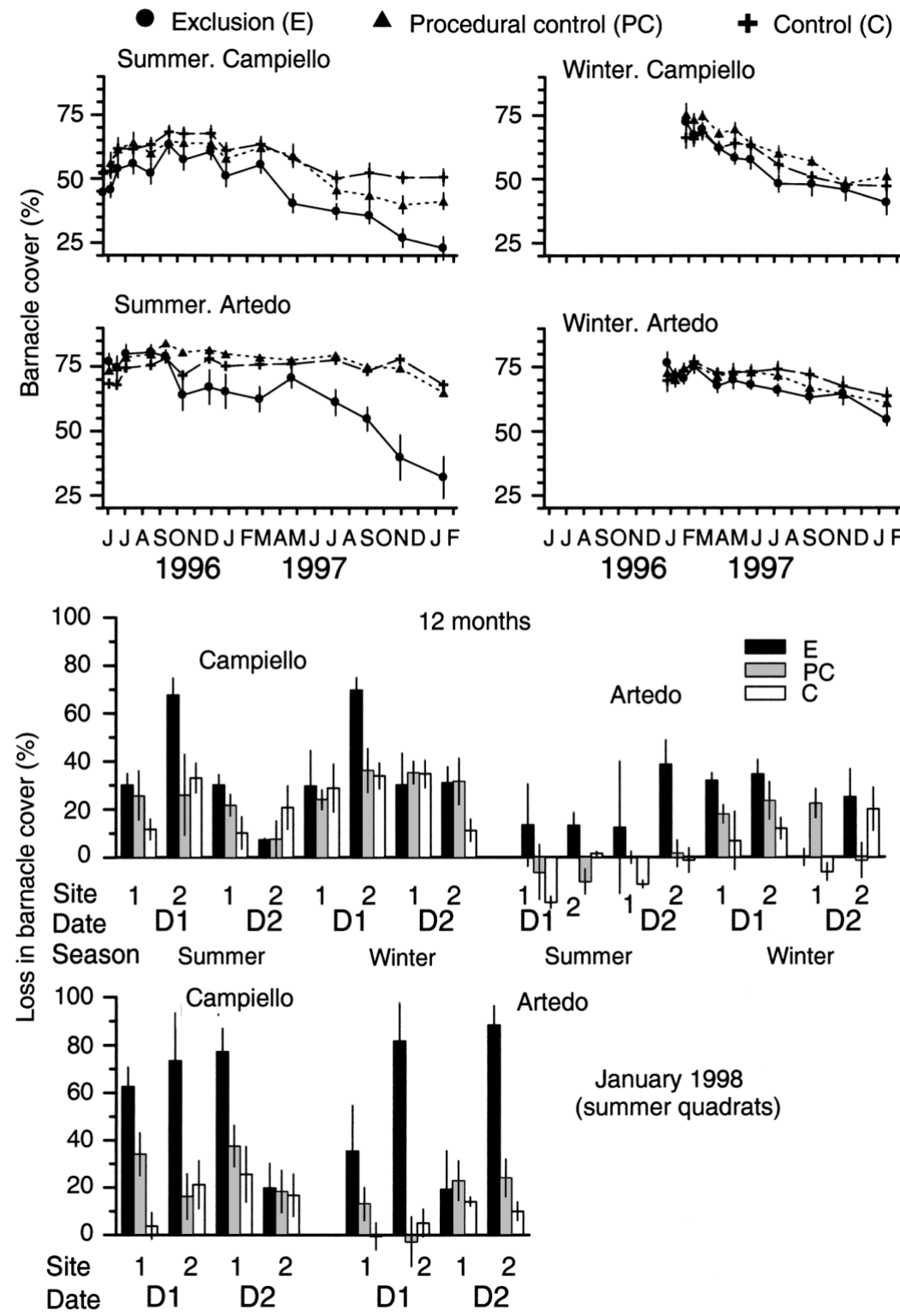


be lost at low numbers of whelks, when whelks were fairly common, the loss of barnacles was always above $50 \%$.

\section{DISCUSSION}

The experimental results supported the hypotheses tested. Changes in the assemblages of the exclusion quadrats were greater than those in both types of controls. Exclusion promoted macroalgal growth and induced the loss of barnacle cover. The ability of limpets to control algal growth and to influence the abundance of other animal species is not at all surprising as there is overwhelming evidence for this worldwide (Underwood \& Jernakoff 1981, see review by Hawkins \& Hartnoll 1983). The relevant aspects are the scales
Table 7. Total number of whelks Thais lapillus recorded in experimental quadrats from June 1996 to January 1998, range of abundance in individual quadrats and number of quadrats in which whelks were recorded at least once (occurrence). Chi-square tests for $2 \times 2$ contingency tables $(\mathrm{df}=1)$ are for differences in occurrence of whelks under different combinations of treatments. There were 48 exclusion quadrats, 48 procedural controls and 47 controls (1 control quadrat was lost) (ns $=$ non significant, $\left.{ }^{* * *} \mathrm{p}<0.001\right)$

\begin{tabular}{|lccc|}
\hline Treatment & Total number & Range & Occurrence \\
\hline Exclusion & 406 & $1-26$ & 32 \\
Procedural control & 80 & $1-37$ & 14 \\
Control & 20 & $1-5$ & 8 \\
$\chi^{2}$ tests & & & \\
$\quad$ Exclusion vs controls & & $25.68^{* * *}$ \\
Among controls & & & $1.97 \mathrm{~ns}$ \\
\hline
\end{tabular}

Table 6. Analyses of differences in the percentage of cover lost by barnacles. After arcsine transformation, variances were still heterogeneous for 12 mo data. Variances were homogeneous after transformation for data in January 1998. One missing replicate and 1 erroneous value were replaced by the mean of the remaining 2 replicates of the same treatment at the same sites and $2 \mathrm{df}$ subtracted from the residual (ns = non-significant, ${ }^{*} \mathrm{p}<0.05,{ }^{* *} \mathrm{p}<0.01,{ }^{* * *} \mathrm{p}<0.001$ )

\begin{tabular}{|c|c|c|c|c|c|c|c|c|c|}
\hline & Source of variation & df & Error term & MS & $F$ & $\mathrm{p}$ & MS & $F$ & $\mathrm{p}$ \\
\hline \multicolumn{4}{|c|}{ (A) All experimental quadrats } & \multicolumn{3}{|c|}{$-12 \mathrm{mo}-$} & \multicolumn{3}{|c|}{ Jan 98} \\
\hline \multirow[t]{3}{*}{ (a) } & Grazing $=\mathrm{G}$ & 2 & & 3262.73 & & & 6436.31 & & \\
\hline & Exclusion vs procedural control & 1 & Pooled-2 & 3269.84 & 8.28 & ** & 5923.25 & 10.68 & ** \\
\hline & Among controls & 1 & Pooled-2 & 433.58 & 1.10 & ns & 1136.57 & 2.05 & ns \\
\hline (b) & Locality $=\mathrm{L}$ & 1 & (h) & 15107.96 & 16.14 & $*$ & 4995.27 & 6.14 & ns \\
\hline (c) & Season $=$ Se & 1 & (f) & 5096.00 & 8.56 & $\mathrm{~ns}$ & 470.70 & 0.61 & ns \\
\hline (d) & $\mathrm{G} \times \mathrm{L}$ & 2 & Pooled-1 & 459.49 & 1.12 & ns & 166.98 & 0.27 & ns \\
\hline \multirow[t]{3}{*}{ (e) } & $\mathrm{G} \times \mathrm{Se}$ & 2 & Pooled-2 & 597.06 & 1.51 & ns & 2041.09 & & \\
\hline & Exclusion vs procedural control $\times \mathrm{Se}$ & 1 & Pooled-2 & & & & 2816.24 & 5.08 & $*$ \\
\hline & Among controls $\times \mathrm{Se}$ & 1 & Pooled-2 & & & & 18.31 & 0.03 & ns \\
\hline (f) & $\mathrm{L} \times \mathrm{Se}$ & 1 & (h) & 595.61 & 0.64 & $\mathrm{~ns}$ & 774.63 & 0.95 & ns \\
\hline (g) & $\mathrm{G} \times \mathrm{L} \times \mathrm{Se}$ & 2 & Pooled-1 & 165.80 & 0.41 & $\mathrm{~ns}$ & 78.62 & 0.13 & ns \\
\hline (h) & Date $=\mathrm{D}(\mathrm{L} \times \mathrm{Se})$ & 4 & (j) & 936.26 & 1.97 & ns & 813.64 & 1.34 & ns \\
\hline (i) & $\mathrm{G} \times \mathrm{D}(\mathrm{L} \times \mathrm{Se})$ & 8 & $(\mathrm{k})$ & 139.61 & 0.26 & ns & 319.31 & 0.41 & ns \\
\hline (j) & Site $=\operatorname{Si}[D(L \times S e)]$ & 8 & (l) & 474.55 & 2.12 & * & 608.16 & 3.05 & ** \\
\hline \multirow[t]{3}{*}{ (k) } & $\mathrm{G} \times \mathrm{Si}[\mathrm{D}(\mathrm{L} \times \mathrm{Se})]$ & 16 & & 543.29 & & & 780.31 & & \\
\hline & Exclusion vs procedural control $\times[\mathrm{D}(\mathrm{L} \times \mathrm{Se})]$ & 8 & (l) & 586.30 & 2.62 & * & 1107.75 & 5.56 & *** \\
\hline & Among controls $\times \mathrm{Si}[\mathrm{D}(\mathrm{L} \times \mathrm{Se})]$ & 8 & (l) & 803.17 & 3.59 & ** & 715.40 & 3.59 & $* *$ \\
\hline \multirow[t]{3}{*}{ (l) } & Residual & 94 & & 223.55 & & & 199.20 & & \\
\hline & Pooled-1 error term: $(\mathrm{i})+(\mathrm{k})$ & 24 & & 408.76 & & & 626.64 & & \\
\hline & Pooled-2 error term: $(\mathrm{d})+(\mathrm{g})+(\mathrm{i})+(\mathrm{k})$ & 28 & & 395.03 & & & 554.66 & & \\
\hline \multicolumn{10}{|c|}{ (B) Summer quadrats in January 1998 (18 mo) } \\
\hline \multirow[t]{3}{*}{ (a) } & Grazing $=\mathrm{G}$ & 2 & & 7763.86 & & & & & \\
\hline & Exclusion vs procedural control & 1 & Pooled-2 & 8454.02 & 12.21 & ** & & & \\
\hline & Among controls & 1 & Pooled-2 & 721.70 & 1.04 & ns & & & \\
\hline (b) & Locality $=\mathrm{L}$ & 1 & (d) & 917.85 & 1.71 & ns & & & \\
\hline (c) & $\mathrm{G} \times \mathrm{L}$ & 2 & Pooled-1 & 189.02 & 0.24 & ns & & & \\
\hline (d) & Date = D $(\mathrm{L})$ & 2 & (f) & 538.15 & 0.65 & ns & & & \\
\hline (e) & $\mathrm{G} \times \mathrm{D}(\mathrm{L})$ & 4 & (g) & 491.35 & 0.54 & ns & & & \\
\hline (f) & Site $=\operatorname{Si}[D(L)]$ & 4 & (h) & 822.24 & 3.15 & $*$ & & & \\
\hline \multirow[t]{3}{*}{ (g) } & $\mathrm{G} \times \operatorname{Si}[\mathrm{D}(\mathrm{L})]$ & 8 & & 918.36 & & & & & \\
\hline & Exclusion vs procedural control $\times \operatorname{Si}[D(L)]$ & 4 & (h) & 1406.93 & 5.38 & ** & & & \\
\hline & Among controls $\times \mathrm{Si}[\mathrm{D}(\mathrm{L})]$ & 4 & (h) & 485.49 & 1.86 & $\mathrm{~ns}$ & & & \\
\hline \multirow[t]{3}{*}{ (h) } & Residual & 46 & & 261.31 & & & & & \\
\hline & Pooled-1 error term: $(e)+(g)$ & 12 & & 776.02 & & & & & \\
\hline & Pooled-2 error term: $(\mathrm{c})+(\mathrm{e})+(\mathrm{g})$ & 14 & & 692.17 & & & & & \\
\hline
\end{tabular}


of variability of this effect, the nature of the interactions behind the measurable effects and how this variability and interactions change over large spatial scales.

An identical experimental design was used to evaluate the effects of grazing on the structure of moderately exposed rocky shores on the west coast of Sweden (Lindegarth et al. 2001). However, a formal comparison of the results from both experiments, although possible, is not useful. Differences in the composition of the intertidal assemblages and contrasting environmental conditions preclude any sensible interpretation of a common statistical analysis since any observed difference might be a consequence of multiple factors. The shores of the north of Spain and the west of Sweden differ in the main key grazer: limpets in Spain and Littorina littorea in Sweden (Cervin \& Åberg 1997, Viejo et al. 1999). Dominant algal groups in Sweden include filamentous and crustose red algae and ephemeral greens (Lindegarth et al. 2001), while virtually no macroalgae are present at mid-tidal levels in northern Spain (Anadón 1983). In addition, obvious different thermal and radiation regimes exist in both places, with ice-scouring being a fairly common event in Sweden. Tides in northern Spain are

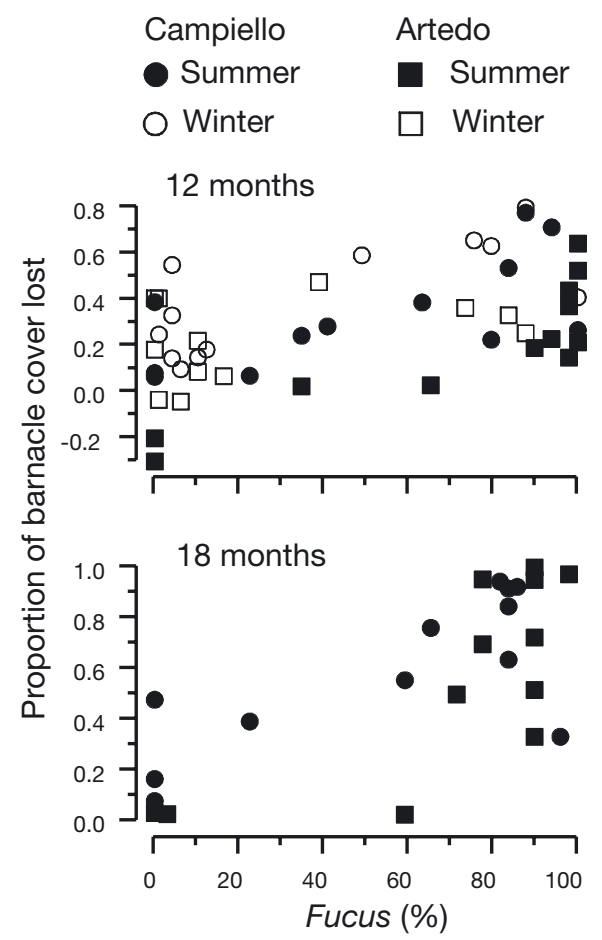

Fig. 8. Relationship between the proportion of barnacle cover lost and cover of Fucus in individual exclusion quadrats 12 and 18 mo after the start of the experiment
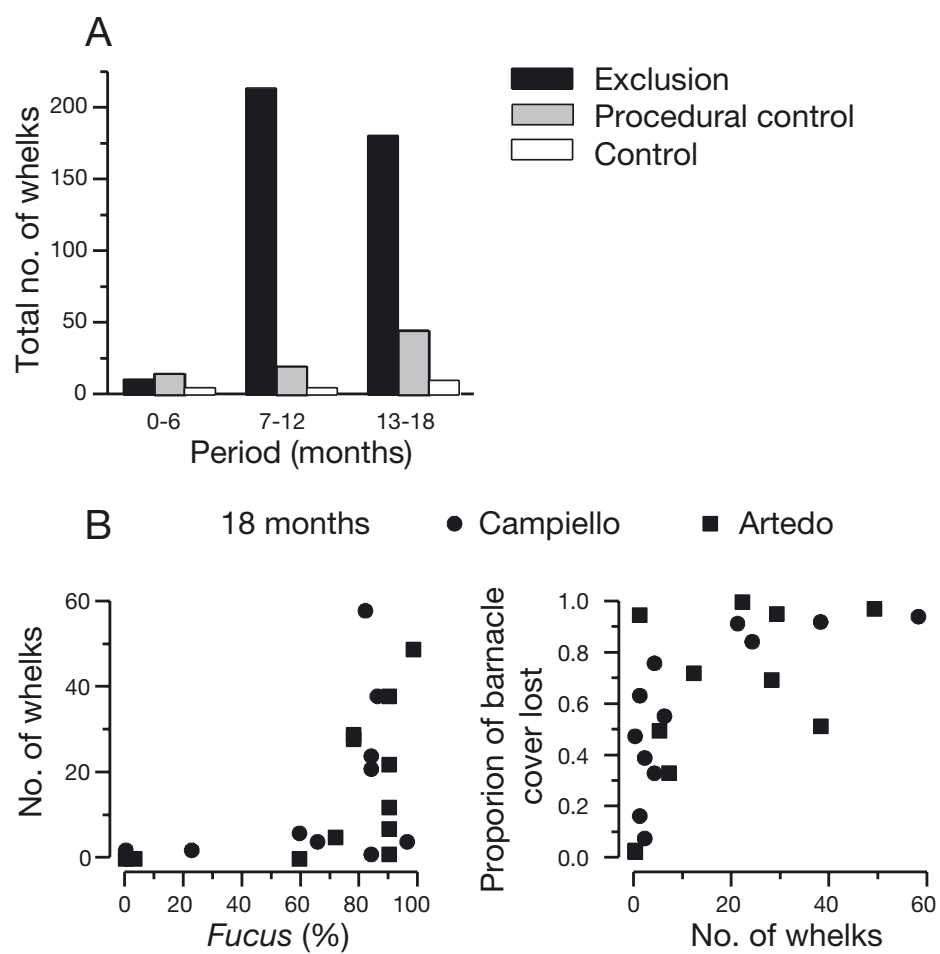

Fig. 9. (A) Total number of whelks counted in different periods during the experiment. For the initial period ( 0 to $6 \mathrm{mo}$ ) data are accumulated numbers from 8 sampling dates. For the periods 7 to 12 and 13 to $18 \mathrm{mo}$, data are accumulated from 3 sampling dates. The period 13 to $18 \mathrm{mo}$ is for quadrats manipulated in summer. (B) Relationship between the accumulated number of whelks and the percentage of cover of Fucus (left) and between the proportion of barnacle loss and accumulated number of whelks (right). In both cases, data are from summer individual quadrats after 18 mo of experimental manipulation

semi-diurnal with a maximum range of $4.3 \mathrm{~m}$, while in Sweden the tidal range is very narrow and often dwarfed by unpredictable sea-level variations (Johannesson 1989). However, qualitative comparisons are possible. Site effects were important in both studies. The role of grazing in the change of the structure of assemblages across dates and sites was weak and inconsistent in Sweden, and it is concluded by Lindegarth et al. (2001) that grazing is less important there than in semi-exposed shores in other parts of the world. Our results support this conclusion as we show that grazing affected the structure of assemblages by limiting the development of ephemerals and algal canopies.

Other studies of the grazing activity of limpets overlap with the experiment reported in this paper. Using wax discs placed on the rock surface in Campiello and Artedo, Jenkins et al. (2001) estimated that an average of $26 \%$ of rock surface was scraped by limpets at natural densities in $2 \mathrm{wk}$, without any seasonal trend and with similar values for both localities. This amount may appear low and, in fact, it is significantly lower 
than estimated rates for southern England or southern Portugal (Jenkins et al. 2001). However, if we consider that an escape size for Fucus is only attained several months after the settlement of zygotes, then it may be enough to prevent the development of a Fucus canopy. In addition, grazing by limpets is not a random process (e.g. Chelazzi et al. 1998b) and the spatial organisation of foraging might be related to the availability of food. The estimated $26 \%$ of rock surface grazed in Jenkins et al. (2001) is a mean value but individual wax discs presented large variability ranging from 0 to virtually $100 \%$ of the surface scraped. If the density of limpets were well below natural levels, the grazing pressure might not be enough to prevent algal growth, in which case the probability of escape of individual algal propagules would increase. No estimates on the efficiency of scraping in removing algal propagules was available, but reports on the effects of limpets on the microflora growing on the rocks in Australia (Underwood \& Jernakoff 1981) or studies on the anatomical structure of the radula (Steneck \& Watling 1982) suggest that scraping may be very efficient. Radula strokes virtually collect all algae from the rock surface.

The experimental design allowed us to test the consistency of the effect of grazing spatially and over time. No effect of start season or date was detected, as the interaction of grazing with these 2 factors was usually not significant. This is possibly due to the low variability in pressure grazing by limpets over time (Jenkins et al. 2001). However, the season of removal had a significant effect on macroalgal growth at 1 locality, resulting in a more rapid colonisation in Artedo during summer than in winter. This may be related to the availability of propagules after the removal of limpets, in a similar mode as season for scraping influenced colonisation of experimental patches by Fucus in British Columbia (Kim \& DeWreede 1996). Twelve and 18 mo after manipulation, however, the significant interaction vanished. In part, this could be due to the method of estimation of macroalgal abundance. By estimating the percentage of cover of macroalgae, differences in abundance under high and low recruitment are only detected at early stages. After some time, as individual plants grow, secondary cover may be similar even with very different density of Fucus plants. However, site effects were significant and surely reflect differences among sites (such as tidal height) independently of experimental manipulations. Apart from Fucus, other algae were abundant in some quadrats, mainly Ralfsia-like soft encrusting species and ephemerals. In general, their abundance decreased as the Fucus canopy developed.

After the last sampling date in October 1998, all fences were removed. Limpets quickly reinvaded the experimental quadrats and after $3 \mathrm{yr}$, all identifiable exclusion quadrats reverted to a situation similar to that before the manipulations. The persistence of dense cover of macroalgae depends upon the continuity of the manipulation and thus the grazer- and barnacle-dominated assemblage and the algal patches cannot be considered alternate stages at these tidal levels (Petraitis \& Dudgeon 1999).

The second prediction, decreased barnacle cover after limpet removal, was also supported by the experimental results. However, the effect was measurable only after 12 mo from the beginning of the manipulations. The lag in the effect is interpreted as only when algal cover was important and persisted for some months did barnacles start to decline. Another relevant result is that the effect of the grazing treatment is sitedependent and presumably reflects site effects in the growth of Fucus and other macroalgae. Results were consistent across seasons, dates and localities. The most recurrent result was that small-scale heterogeneity was important (significant site effects). Site effects might reflect environmental differences among sites. Before manipulations, sites exhibited differences in barnacle cover and abundance of limpets. In addition, they had different mean tidal heights but were similar in orientation, slope and roughness. Other factors, which could potentially influence the composition and dynamics of the assemblage, such as the prevailing direction of waves or exposure were not investigated. Site effects may be generated by multiple factors acting independently or synergistically. Tidal height alone may influence the growth rate of algal propagules (Raffaelli \& Hawkins 1996). The direction of incoming waves and the distance to sources of propagules may affect not only the rate of development of algal canopies but also the possibility that some algae (e.g. Fucus) could even reach individual experimental quadrats (Arrontes 2002).

There is another effect related to limpet removal: increased densities of trochids (mainly Gibbula umbilicalis). In this case, a clear interpretation is not possible. The increased density might be an indirect effect caused either by the increase of food on the rock surface or by the growth of macroalgae, but no relationship between abundance of algae and trochids was found. Alternatively, this increase in trochid density might be an artefact. Grazers have been observed to be attracted by fences and open cages in previous studies (e.g. Underwood 1980). A similar trend of increased density in procedural controls was also observed in limpets and whelks. Some evidence of artefacts also appeared in barnacle cover. Potential artefacts were not always statistically significant, but in most cases differences between both types of controls were always in the same direction. Significant effects of procedural controls, even with clear exclusion effects, may gener- 
ate results that are not logically interpretable (Underwood 1997). In general, however, and due to the magnitude of the change in exclusion quadrats vs procedural controls, we do not think that artefacts were strong enough to invalidate the main conclusions.

Both direct and indirect effects are responsible for the observed results. The increase of algae is surely an immediate consequence of the cessation of limpet grazing and is interpreted as a direct effect. Several lines of evidence, however, suggest indirect effects on barnacles: (1) Limpets have been shown to remove juvenile and larvae of barnacles, either by accidental or deliberate ingestion or by dislodging specimens while crawling over the barnacles (e.g. Wootton 1993). If a measurable direct effect on barnacles existed it should be negative and thus removal of limpets should promote an increase in barnacle cover. (2) Towards the end of the experiment, the rate of loss of barnacles was positively related to algal cover in exclusion quadrats. The direct causes might include overgrowth of barnacles by algae, reduced water flow limiting availability of food and inhibition of recruitment. (3) Sporadically, juvenile whelks were found among algae in exclusion quadrats more often than in controls. The latter effect was also observed in previous studies such as the monitoring program of the effects of the Torrey Canyon oil spill (summarised in Raffaelli \& Hawkins 1996). Juvenile whelks in Campiello and Artedo tend to aggregate among algae, crevices or underneath boulders, particularly on clear sunny days (B. Martínez, unpubl.). In short, the indirect effect of limpets on barnacles should be positive and mediated by the inhibition of algal growth. Similarly, the effects of algae on barnacles may be complex and include additional indirect effects mediated by increasing abundance of juvenile whelks.

Indirect effects appear to be common in intertidal systems. Menge (1995) estimated that 40 to $50 \%$ of the changes occurring after perturbations might be due to indirect effects. Indirect effects include a great variety of species interactions but all of them can be grouped into 9 types (Menge 1995). Habitat facilitation is one of these types and occurs when one species improves the habitat of another species by altering the abundance of a third species (Fairweather 1990). Habitat facilitation appears to be the type of indirect effect of limpets on barnacles described in this work. There are many examples of indirect effects in intertidal communities (see Menge 1995 for references). For example, in the San Juan Islands (Washington), removal of macroalgae by chitons enhances the growth of microalgae, which are the food for acmaeid limpets (Dethier \& Duggins 1984).

Unambiguous identification of indirect effects demands proper experimental designs involving at least 2 factors in a crossed design (Anderson 1999): (1) ma- nipulation of abundance (e.g. presence/absence) of the species assumed to exert the indirect effect and (2) manipulation of the abundance of the third species directly responsible for changes in the abundance of the focal species. Additional treatments should control for artefacts associated with manipulations. To conclude that a decrease in barnacle cover is not a direct consequence of limpet removal but of the growth of macroalgae, 2 additional experimental treatments should consider the growth of macroalgae while limpets were still present, and the removal of limpets with no growth of algae. No experiments of this kind were performed in this work to identify indirect effects and it is difficult to see how these treatments could be set up. However, considering the reported evidence based on correlations and life-cycles, we are confident that indirect effects exist.

Our results are summarised in Fig. 10. We present averaged species interactions but in some sites or quadrats the picture may be completely different, as in some quadrats no growth of macroalgae occurred and barnacle cover remained unchanged. Of course, there are more links in the assemblage than those in Fig. 10. For instance, limpets have been shown to have a small deleterious effect on barnacles, and whelks are often observed to feed on juvenile limpets (B. Martínez, pers. obs.). In addition, the interactions between canopy $\mathrm{Fu}$ cus and limpets may be complex and generate cycles (Hawkins \& Hartnoll 1983, Burrows \& Hawkins 1998). The graph is also incomplete because other groups are ignored; the complete assemblage should include small littorinids, acari, insects, grapsid crabs, and interspersed Lychina pygmaea and Mytilus patches with their associated fauna. Fig. 10 only represents a subset of a more complex assemblage and a conspicuous spatial heterogeneity. Finally, the graph would only be complete if the pattern of arrival of algal propagules and larvae could be incorporated. It is evident that

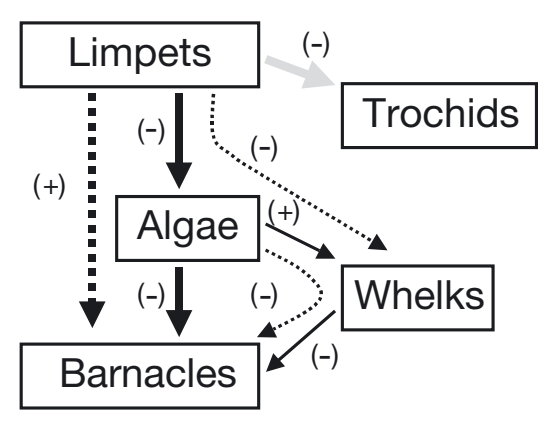

Fig. 10. Summary of species interactions at mid-tidal levels in northern Spain suggested by various evidence in this paper. Only groups and links investigated in this paper are presented. Continuous lines: direct effects; discontinuous lines: indirect effects; grey line: doubtful effect. The thickness of the lines relates to intensity of the effect 
much additional work is needed for the unambiguous identification and quantification of direct and indirect effects, for the identification of the causes of the site effects and to discover the role of the species ignored in this work.

Acknowledgements. The experiment was funded by the European Union as a part of the EUROROCK-project, MAS3CT95-0012.

\section{LITERATURE CITED}

Anadón R (1983) Zonación en la costa asturiana: variación longitudinal de las comunidades de macrófitos en diferentes niveles de marea. Invest Pesq 47:125-141

Anadón R, Niell FX (1981) Distribución longitudinal de macrófitos en la costa asturiana ( $\mathrm{N}$ de España). Invest Pesq 45:143-156

Anderson MJ (1999) Distinguishing direct from indirect effects of grazers in intertidal estuarine assemblages. J Exp Mar Biol Ecol 234:199-218

Anderson MJ (2001) A new method for non-parametric multivariate analysis of variance. Aust Ecol 26:32-46

Anderson MJ (2003) DISTLM v.2: a FORTRAN computer program to calculate a distance-based multivariate analysis for a linear model. Department of Statistics, University of Auckland, New Zealand

Anderson MJ, Underwood AJ (1997) Effects of gastropod grazers on recruitment and succession of an estuarine assemblage: a multivariate and univariate approach. Oecologia 109:442-453

Arrontes J (1993) Nature of the distributional boundary of Fucus serratus on the north shore of Spain. Mar Ecol Prog Ser 93:183-193

Arrontes J (2002) Mechanisms of range expansion in the intertidal brown alga Fucus serratus in northern Spain. Mar Biol 141:1059-1067

Benedetti-Cecchi L, Cinelli F (1994) Recovery of patches in an assemblage of geniculate coralline algae: variability at different successional stages. Mar Ecol Prog Ser 110:9-18

Benedetti-Cecchi L, Cinelli F (1997) Confounding in field experiments: direct and indirect effects of artefacts due to the manipulation of limpets and macroalgae. J Exp Mar Biol Ecol 209:171-184

Benedetti-Cecchi L, Bulleri F, Cinelli F (2000) The interplay of physical and biological factors in maintaining mid-shore and low-shore assemblages on rocky coasts in the northwest Mediterranean. Oecologia 123:406-417

Boaventura D, Alexander M, Della Santina P, Smith ND, Ré P, Cancela da Fonseca L, Hawkins SJ (2002) The effects of grazing on the distribution and composition of low-shore algal communities on the central coast of Portugal and on the southern coast of Britain. J Exp Mar Biol Ecol 267:185-206

Burrows MT, Hawkins SJ (1998) Modelling patch dynamics on rocky shores using deterministic cellular automata. Mar Ecol Prog Ser 167:1-13

Cervin G, Åberg P (1997) Do littorinids affect the survival of Ascophyllum nodosum germlings? J Exp Mar Biol Ecol 218:35-47

Chelazzi G, Hawkins SJ, Åberg P, Arrontes J, Myers A, Paula $\mathrm{J}$ (1998a) Interactions of physical and biological factors in the surf and swash zone of European rocky shores. In: Barthel KG, Barth H, Bohle-Carbonell M, Fragakis C, Lipiatou E, Martin P, Ollier G, Weydert M (eds) Third
European Marine Science and Technology Conference, Lisbon, 23-27 May 1998: Project synopses, Vol 1: Marinesystems. European Commission DG 12, Luxembourg, p 361-376

Chelazzi G, Santini G, Della Santina P (1998b) Route selection in the foraging of Patella vulgata (Mollusca: Gastropoda). J Mar Biol Assoc UK 78:1223-1232

Dayton PK, Tegner MJ, Parnell PE, Edwards PB (1992) Temporal and spatial patterns of disturbance and recovery in a kelp forest community. Ecol Monogr 62:421-445

Dethier MN, Duggins DO (1984) An 'indirect commensalism' between marine herbivores and the importance of competitive hierarchies. Am Nat 124:205-219

Dethier MN, Duggins DO (1988) Variation in strong interactions in the intertidal zone along a geographical gradient: a Washington-Alaska comparison. Mar Ecol Prog Ser 50: 97-105

Fairweather PG (1990) Is predation capable of interacting with other community processes on rocky reefs? Aust J Ecol 15:453-464

Farrell TM (1991) Models and mechanisms of succession: an example from a rocky intertidal community. Ecol Monogr 61:95-113

Foster MS (1990) Organization and macroalgal assemblages in the Northeast Pacific: the assumption of homogeneity and the illusion of generality. Hydrobiologia 192:21-33

Hawkins SJ (1981) The influence of season and barnacles on the algal colonization of Patella vulgata exclusion areas. J Mar Biol Assoc UK 61:1-15

Hawkins SJ, Hartnoll RG (1983) Grazing of intertidal algae by marine invertebrates. Oceanogr. Mar Biol Annu Rev 21: 195-282

Hawkins SJ, Harnoll RG, Kain JM, Norton TA (1992) Plantanimal interactions on hard substrata in the north-east Atlantic. In: John DM, Hawkins SJ, Price JH (eds) Plantanimal interactions in the marine benthos. Clarendon Press, Oxford, p 1-32

Jenkins SR, Arenas F, Arrontes J, Bussell J and 10 others (2001) European-scale analysis of seasonal variability in limpet grazing activity and microalgal abundance. Mar Ecol Prog Ser 211:193-203

Johannesson K (1989) The bare zone of Swedish rocky shores: why is it there? Oikos 54:77-86

Johnson LE (1992) Potential and peril of field experimentation: the use of copper to manipulate molluscan herbivores. J Exp Mar Biol Ecol 160:251-262

Kennelly SJ (1987) Physical disturbances in an Australian kelp community. I. Temporal effects. Mar Ecol Prog Ser 40: 145-153

Kim JH, DeWreede RE (1996) Effects of size and season of disturbance on algal patch recovery in a rocky intertidal community. Mar Ecol Prog Ser 133:217-228

Lindegarth M, Åberg PA, Cervin G, Nilsson PG (2001) Effects of grazing on the structure of mid-shore, intertidal assemblages on moderately exposed rocky shores on the Swedish west coast. Mar Ecol Prog Ser 212:29-38

Litell RC, Milliken GA, Striuo WW, Wolfinger RD (1996) SAS system for mixed models. SAS Institute, Cary, NC

McArdle BH, Anderson MJ (2001) Fitting multivariate models to community data: a comment on distance-based redundancy analysis. Ecology 82:290-297

Menge BA (1995) Indirect effects in marine rocky intertidal interaction webs: patterns and importance. Ecol Monogr 65:21-74

Petraitis PS, Dudgeon SR (1999) Experimental evidence for the origin of alternative communities on rocky intertidal shores. Oikos 84:239-245 
Raffaelli D, Hawkins S (1996) Intertidal ecology. Chapman \& Hall, London

Robles CD, Cubit J (1981) Influence of biotic factors in an upper intertidal community: dipteran larvae grazing on algae. Ecology 62:1536-1547

SAS (1996) SAS/SYSTAT software: changes and enhancements through release 6.11. SAS Institute, Cary, NC

Steneck RS, Watling L (1982) Feeding capabilities and limitation of herbivore molluscs: a functional group approach. Mar Biol 68:299-319

Stephenson TA, Stephenson A (1972) Life between tidemarks on rocky shores. WH Freeman, San Francisco

Underwood AJ (1978) An experimental evaluation of competition between three species of intertidal gastropods. Oecologia (Berl) 33:185-202

Underwood AJ (1980) The effects of grazing by gastropods and physical factors on the upper limits of distribution of intertidal macroalgae. Oecologia (Berl) 46:201-213

Underwood AJ (1984) Vertical and seasonal patterns in competition for microalgae between intertidal gastropods. Oecologia (Berl) 64:211-222

Editorial responsibility: Antony Underwood (Contributing Editor), Sydney, Australia
Underwood AJ (1997) Experiments in ecology. Their logical design and interpretation using analysis of variance. Cambridge University Press, Cambridge

Underwood AJ, Jernakoff P (1981) Effects of interactions between algae and grazing gastropods on the structure of a low-shore intertidal algal community. Oecologia (Berlin) 48:221-233

Underwood AJ, Petraitis PS (1993) Structure of intertidal assemblages in different locations: how can local processes be compared? In: Ricklefs R, Schluter D (eds) Species diversity in ecological communities. University of Chicago Press, Chicago, p 38-51

Viejo RM, Åberg P, Cervin G, Lindegarth M (1999) The interactive effects of adult canopy, germling density and grazing on germling survival of the rockweed Ascophyllum nodosum. Mar Ecol Prog Ser 187:113-120

Winer BJ (1971) Statistical principles in experimental design, 2nd edn. McGraw-Hill, New York

Wootton JT (1993) Indirect effects and habitat use in an intertidal community: interaction chains and interaction modifications. Am Nat 141:71-89

Submitted: April 29, 2003; Accepted: April 21, 2004

Proofs received from author(s): August 6, 2004 